\title{
Paternal care behaviors of Japanese giant salamander Andrias japonicus in natural populations
}

\author{
Sumio Okada $\cdot$ Yukihiro Fukuda $\cdot$ \\ Mizuki K. Takahashi
}

Received: 27 November 2013/Accepted: 17 July 2014/Published online: 12 November 2014

(C) Japan Ethological Society and Springer Japan 2014

\begin{abstract}
Parental care among salamanders is typically provided by females. A rare case of parental care by male salamanders appears to occur in Cryptobranchidae. Yet, paternal behaviors have rarely been reported from natural populations of any Cryptobranchid salamanders, and their adaptive significance is poorly understood. The present study aimed to examine paternal care behaviors in a fully aquatic Japanese giant salamander (Andrias japonicus) in situ. At the beginning of the summer breeding season, large males, called den-masters, occupy burrows along stream banks for breeding and nesting. We videotaped post-breeding behaviors of two den-masters that stayed with the eggs, one in a natural and the other in an artificial nest in natural streams. We identified three behaviors, tail fanning, agitating and egg eating, to be parental care. Tail fanning provides oxygenated water for the eggs. We found that the den-master in the artificial nest, where dissolved oxygen level was lower, displayed tail fanning more frequently. Agitating the eggs with its head and body likely prevents yolk adhesions. The den-masters selectively ate
\end{abstract}

Electronic supplementary material The online version of this article (doi:10.1007/s10164-014-0413-5) contains supplementary material, which is available to authorized users.

S. Okada $(\bowtie)$

Department of Social Systems Engineering, Tottori University,

Tottori 680-8552, Japan

e-mail: okadasumio@gmail.com

Y. Fukuda

Nichinan Hanzaki Dojo, Niiya, Nichinan-cho, Tottori 689-5225,

Japan

M. K. Takahashi

Department of Biology, Bucknell University, Lewisburg,

PA 17837, USA whiter eggs that appeared to be dead or infected with water mold. This behavior, which we termed hygienic filial cannibalism, likely prevents water mold from spreading over healthy eggs. Digital video images relating to this article are available at http://www.momo-p.com/showde tail-e.php?movieid=momo140906aj01a, http://www.momop.com/showdetail-e.php?movieid=momo140906aj02a, http:// www.momo-p.com/showdetail-e.php?movieid=momo1409 06aj03a and http://www.momo-p.com/showdetail-e.php? movieid=momo140906aj04a.

Keywords Agitating eggs $\cdot$ Andrias japonicus $\cdot$ Egg attendance · Filial cannibalism · Paternal care .

Salamander - Tail fanning - Water mold infection

\section{Introduction}

Parental care is ubiquitous in a wide range of animal species from insects to mammals, and its diverse forms and adaptive significance have received much attention (e.g., Trivers 1972; Clutton-Brock 1991; Andersson 1994). Parental care in Caudata is common across most families and generally associated with terrestrial reproductive patterns in which females attend smaller clutches of larger ova (Salthe and Mecham 1974; Nussbaum 1985; Duellman and Trueb 1986; Crump 1996). Maternal care in salamanders is also associated with internal fertilization (Trivers 1972; Dawkins and Carlisle 1976; Gross and Shine 1981). A notable exception to this general trend of parental care in salamanders appears to be found in Cryptobranchidae, which consists of two genera and three species: hellbender (Cryptobranchus alleganiensis), Chinese giant salamander (Andrias davidianus), and Japanese giant salamander (A. japonicus). Cryptobranchid salamanders fertilize eggs 
externally and likely share similar mating habits (Nussbaum 1985). A few anecdotal reports suggest that males of C. alleganiensis and A. japonicus attend their eggs and protect them from predators and conspecific egg cannibals (Smith 1907; Tago 1927). This rare case of possible parental care by male salamanders begs for more detailed and quantitative examinations.

Giant salamanders in Cryptobranchidae are fully aquatic and live in lotic freshwater habitats. During the summer breeding season, typically in August and September, males of A. japonicus actively find and occupy suitable courtship and nesting sites, which are typically hidden burrows along stream banks with narrow openings (Kuwabara et al. 2005; Kuwabara and Nakagoshi 2009). Only larger males called den-masters are able to occupy suitable sites. While a denmaster guards the den against other males and sexually inactive females, he allows a sexually active female to enter his den (Kuwabara and Nakagoshi 2009). As mating begins with oviposition and sperm release, smaller satellite males often join the mating, and thus a single female typically mates with multiple males in a den. As the mating ceases, the female and the satellite males leave the den. A female produces 300-600 eggs per spawn in the form of two beaded strings (Tago 1927; Kobara 1985). The denmaster remains in the courtship site with the fertilized eggs and often mates with multiple females sequentially during a single breeding season (Kobara 1985; Kawamichi and Ueda 1998; Kuwabara et al. 2005; Kuwabara and Nakagoshi 2009). It is unknown whether females or satellite males visit multiple dens. The den-master aggressively attacks possible predators (e.g., fish and turtles) and other conspecific males that may cannibalize the eggs, suggesting paternal egg attendance (Tago 1927). However, an alternative explanation is that the den-master is simply guarding his den for future mating opportunities and also as his regular burrow in which to hide. This explanation becomes plausible when not only the den-master but also multiple satellite males contribute to the paternity of the fertilized eggs, but no data are available to date about the den-master's reproductive success relative to those of the satellite males.

Other than Tago (1927), only a few husbandry notes (available only in Japanese) briefly describe possible paternal care behaviors such as tail fanning and agitation of the eggs (Suzuki 1981, 1984). In sum, the notion that male A. japonicus provides parental care is based on two lines of rather insufficient evidence: (1) nest or egg defense in nature and (2) brief descriptions of tail fanning and agitation of the eggs in captivity. Thus, despite the prevailing belief of paternal care in $A$. japonicus, there are few empirical studies. In particular, studies that examined paternal care under natural conditions are lacking for any of the giant salamander species.
The aim of the present study is to examine parental care of male A. japonicus by observing post-breeding behaviors of den-masters in their nesting sites in situ. We surveyed two den-masters and videotaped their behaviors one in a natural nest and the other in an artificial nest. We also quantified the frequencies of displayed behaviors to examine the possible behavioral differences between the two nests. Because the artificial nest, which was constructed for conservation purposes, was installed $2 \mathrm{~m}$ from the main stream using a connecting concrete pipe, we predicted lower dissolved oxygen (DO) level in the artificial than in the natural nest along the stream bank. Accordingly, this potential difference in DO may affect den-master's behaviors differently. We finally discussed the adaptive significance of the observed behaviors.

\section{Materials and methods}

\section{Videotaping}

During September and October 2010, we videotaped the behaviors of two den-masters: one in an artificial nest in Ichikawa River, Hyogo Prefecture $\left(35^{\circ} 12^{\prime} \mathrm{N}, 134^{\circ} 52^{\prime} \mathrm{E}\right.$, elevation $446 \mathrm{~m}$ ) and the other in a natural nest in Hino River, Tottori Prefecture, Japan $\left(35^{\circ} 05^{\prime} \mathrm{N}, 133^{\circ} 11^{\prime} \mathrm{E}\right.$, elevation $472 \mathrm{~m}$ ). Total body lengths of the den-masters were 106 and $88 \mathrm{~cm}$ in the artificial and natural nests, respectively. We used a Sony Handycam HDR-XR500V with SONY sports pack SPK-HCE waterproof housing and a Canon iVIS HF-11 with Seatool iVIS HF-11 waterproof housing. The artificial nest $(60 \mathrm{~cm}$ diameter $\times 160 \mathrm{~cm}$ height) was installed by Hyogo Prefecture in 1994 for the purpose of conservation (Tochimoto 1995). This nest is equipped with a removable lid, which allowed us to videotape a salamander inside the nest. We videotaped the denmaster in the natural nest by placing the recorder in front of the nest entrance. The natural nest den-master spent on average $1.3 \mathrm{~min}$ per day outside the den (total recording time $=11 \mathrm{~h} 26 \mathrm{~min}$ ). The artificial nest den-master spent on average $125 \mathrm{~min}$ per day outside of the den $(24 \mathrm{~h}$ $19 \mathrm{~min})$. We do not have their behavioral data outside of the den, and thus it is difficult to interpret this time difference. Therefore, we removed the time when the den-masters were not in the nests from the analyses. After removing the outside-den time, the total recording time of the artificial nest den-master's behaviors was $16 \mathrm{~h}(2 \mathrm{~h} 53$ min daytime and $13 \mathrm{~h} 7 \mathrm{~min}$ nighttime) over 4 days (1, 5, 12 and 23 October) and that of the natural nest den-master's behaviors was $11 \mathrm{~h} 19 \mathrm{~min}$ ( $2 \mathrm{~h} 12 \mathrm{~min}$ daytime and $9 \mathrm{~h} 7 \mathrm{~min}$ nighttime) over 5 days (6, 17, and 27 September, and 1 and 12 October). Oviposition occurred on 31 August in the natural nest and in mid-September in the artificial nest. 
Table 1 A list of action patterns displayed by two male Andrias japonicus that stayed with fertilized eggs in their nests. Video clips are also provided for three action patterns, tail fanning (S1: http:// www.momo-p.com/showdetail-e.php?movieid=momo140906aj01a), agitating (S2: http://www.momo-p.com/showdetail-e.php?movieid= momo140906aj02a), and egg eating (S3: http://www.momo-p.com/ showdetail-e.php?movieid=momo140906aj03a), which likely increase the survivorship of the eggs (i.e., parental care)

\begin{tabular}{|c|c|}
\hline $\begin{array}{l}\text { Action } \\
\text { patterns }\end{array}$ & Description \\
\hline $\begin{array}{l}\text { Tail } \\
\text { fanning }\end{array}$ & $\begin{array}{l}\text { Lateral undulating movement of the tail within a } \\
\text { cluster of eggs (S1) }\end{array}$ \\
\hline Rocking & $\begin{array}{l}\text { Lateral slow movement of the body with all four limbs } \\
\text { grounded on the same positions }\end{array}$ \\
\hline Agitating & $\begin{array}{l}\text { Irregular, often vigorous movement of the head or } \\
\text { body within a cluster of eggs (S2) }\end{array}$ \\
\hline Egg eating & $\begin{array}{l}\text { Consumption of a single egg that shows the sign of } \\
\text { unfertilization, death, or water mold infection (white } \\
\text { eggs), often following agitating behavior (S3) }\end{array}$ \\
\hline Breathing & Lifting of the head up to the water surface to breath \\
\hline Staying still & Staying still \\
\hline Others & $\begin{array}{l}\text { Opening and closing its mouth for no obvious reasons, } \\
\text { moving in and out of the nest, eating own shed skin, } \\
\text { eating gelatinous string-like structures connecting } \\
\text { eggs, moving leaves and twigs with its mouth, } \\
\text { following moving snails }\end{array}$ \\
\hline
\end{tabular}

\section{Behavioral data analyses}

We examined the video clips and classified the behaviors displayed by the two den-masters into seven action patterns: (1) tail fanning, (2) rocking, (3) agitating, (4) egg eating, (5) breathing, (6) staying still, and (7) other (Table 1; Fig. 1). We calculated the proportion of each behavior displayed per day, arcsin-transformed the data (McDonald 2009), and used $t$ tests to examine whether there were any differences in the displayed behaviors in proportion over the recorded days between the artificial and natural nest den-masters. Prior to $t$ tests, we confirmed that the data distribution in each behavioral category was normal. It was ideal to study several den-masters from each nest type to assure data independency. Because of the difficulty in finding nesting sites of A. japonicus in nature (see "Discussion"); however, we analyzed the data from only one den-master from each nest type as explained above.

We observed tail fanning in both the natural and artificial nests. Accordingly, we made a detailed examination of duration and rate of tail fanning between the two nests using the data collected on 1 October because this was the only day we recorded the den-master's behaviors on the same day during the same period (i.e., daytime). Because both the duration and rate of tail fanning in the artificial nest were not normally distributed, we used non-parametric
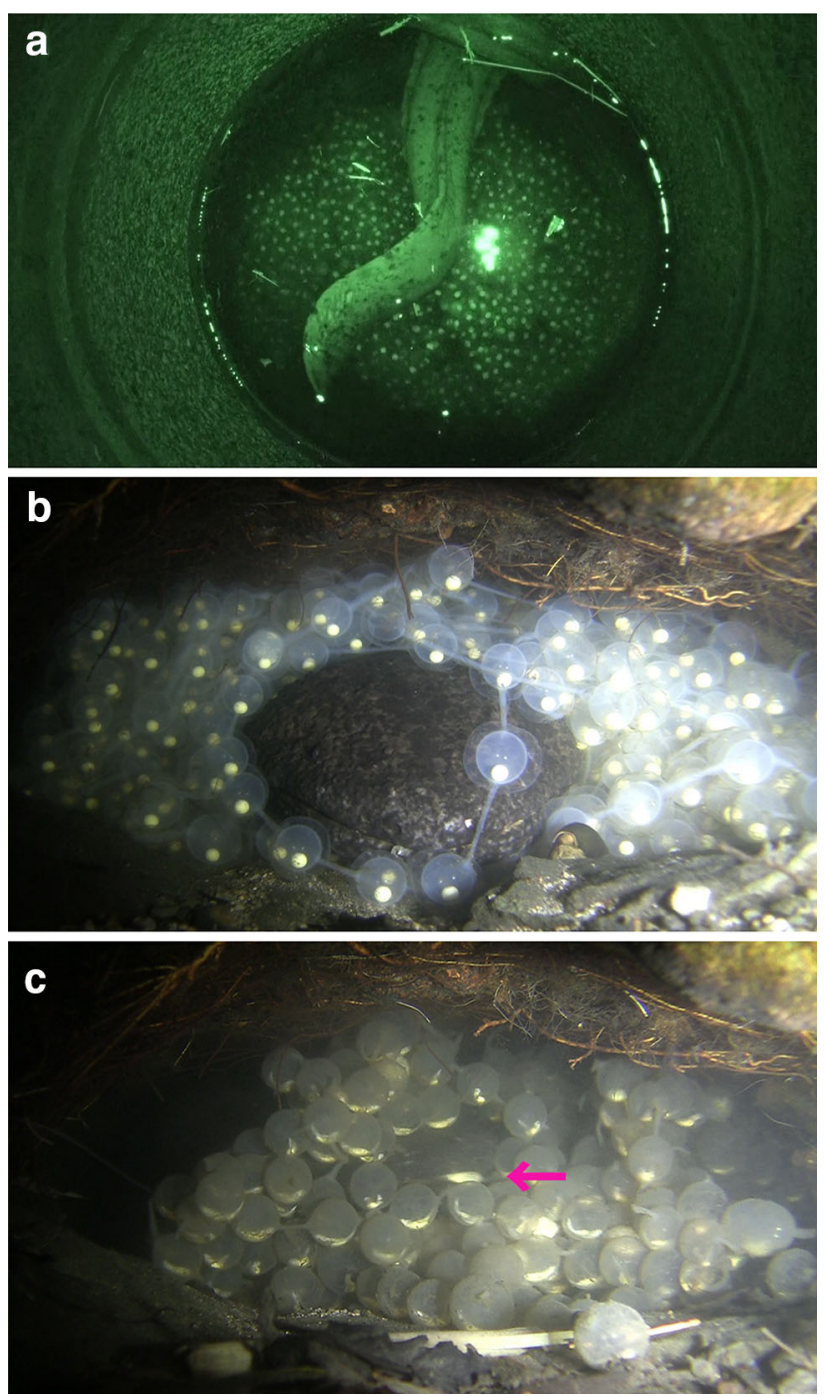

Fig. 1 Three action patterns of male Andrias japonicus observed in its nest: a tail fanning by the artificial nest den-master (S1: recorded on 1 October 2010, http://www.momo-p.com/showdetail-e.php?mo vieid=momo140906aj01a), b agitating by the natural nest den-master (S2: recorded on 6 September 2010, http://www.momo-p.com/show detail-e.php?movieid=momo140906aj02a), and c egg eating by the natural nest den-master (S3: recorded on 1 October 2010, http://www. momo-p.com/showdetail-e.php?movieid=momo140906aj03a). In (c), the arrow indicates the white egg in the mouth of the den-master, which appeared to be dead, unfertilized, or infected with water mold

Mann-Whitney $U$ tests to compare duration and rate of tail fanning between the natural and artificial nests.

Dissolved oxygen measurement

We used iodometric titration analyses to measure dissolved oxygen of the main streams and nesting sites of Ichikawa (artificial nest) and Hino (natural nest) River three times (Ichikawa: 11 and 30 July, and 21 August 2011; Hino: 3 July, 28 August, and 25 September, 2011). We used $t$ tests 
Table 2 Statistical comparisons, percentages, means and standard errors of seven action patterns displayed by a male Andrias japonicus (denmaster) staying with eggs during 4-day recording in the artificial, and 5-day recording in the natural nest in 2010

\begin{tabular}{lllllllll}
\hline & $\begin{array}{l}\text { Tail fanning } \\
(\%)\end{array}$ & $\begin{array}{l}\text { Rocking } \\
(\%)\end{array}$ & $\begin{array}{l}\text { Agitating } \\
(\%)\end{array}$ & $\begin{array}{l}\text { Egg eating } \\
(\%)\end{array}$ & $\begin{array}{l}\text { Breathing } \\
(\%)\end{array}$ & $\begin{array}{l}\text { Staying still } \\
(\%)\end{array}$ & $\begin{array}{l}\text { Others } \\
(\%)\end{array}$ & $\begin{array}{l}\text { Total recorded time } \\
(\mathrm{s})\end{array}$ \\
\hline $\begin{array}{c}\text { Statistical } \\
\text { results }\end{array}$ & $\begin{array}{l}t=6.903 \\
P<0.001^{*}\end{array}$ & $\begin{array}{l}t=2.928 \\
P=0.043\end{array}$ & $\begin{array}{l}t=1.394 \\
P=0.206\end{array}$ & $\begin{array}{l}t=2.016 \\
P=0.101\end{array}$ & $\begin{array}{l}t=1.499 \\
P=0.178\end{array}$ & $\begin{array}{l}t=4.552 \\
P=0.003 *\end{array}$ & N/A & N/A \\
Artificial & & & & & & & \\
1 Oct & 53.65 & 0.00 & 17.24 & 0.76 & 0.39 & 23.66 & 4.31 & 10008.00 \\
5 Oct & 43.30 & 0.00 & 12.02 & 0.43 & 0.59 & 42.82 & 0.83 & 26418.00 \\
12 Oct & 24.42 & 0.00 & 40.68 & 3.59 & 1.39 & 28.70 & 1.21 & 10412.00 \\
23 Oct & 42.62 & 0.00 & 32.72 & 2.30 & 0.00 & 21.89 & 0.47 & 10759.00 \\
Ave & 41.00 & 0.00 & 25.66 & 1.77 & 0.59 & 29.27 & 1.70 & 14399.25 \\
SE & 6.07 & 0.00 & 6.66 & 0.73 & 0.29 & 4.74 & 0.88 & 4009.19 \\
Natural & & & & & & 51.04 & 13.38 & 7663.00 \\
6 Sep & 1.68 & 2.28 & 28.76 & 2.86 & 0.00 & 71.02 & 6.82 & 7972.00 \\
17 Sep & 0.00 & 5.31 & 7.75 & 8.61 & 0.49 & 66.30 & 5.82 & 8403.00 \\
27 Sep & 0.00 & 2.43 & 13.21 & 12.06 & 0.19 & 48.85 & 9.42 & 7061.00 \\
1 Oct & 1.64 & 11.29 & 20.22 & 8.44 & 0.14 & 69.88 & 4.48 & 9720.00 \\
12 Oct & 5.27 & 14.34 & 5.95 & 0.00 & 0.09 & 61.42 & 7.98 & 8163.80 \\
Ave & 1.72 & 7.13 & 15.18 & 6.39 & 0.18 & 4.76 & 1.57 & 446.25 \\
SE & 0.96 & 2.43 & 4.21 & 2.17 & 0.08 & & \\
\hline
\end{tabular}

* Statistically significant differences $(\alpha=0.0083$ after Bonferroni correction)

to examine whether there were any differences in DO levels in the main stream and nesting site between the two streams. Prior to $t$ tests, we confirmed that the data distributions were all normal.

\section{Results}

\section{Den-master behavior}

The natural nest den-master displayed all six major behaviors, whereas the artificial nest den-master displayed all but rocking behavior (Table 2). The two den-masters differed in the percentages of the displayed behaviors (Table 2). After Bonferroni correction $(\alpha=0.05 /$ $6=0.0083)$, we found that the artificial nest den-master displayed proportionally more tail fanning $(t=7.214$, $d f=7, P<0.001)$ and less staying-still behavior $(t=-$ 4.715, $d f=7, P=0.002$ ) than the natural nest den-master. There were no significant differences in the other behaviors.

We observed tail fanning 159 times in the artificial nest and four times in the natural nest on 1 October. The duration of each tail fanning event was similar between the artificial (mean $\pm \mathrm{SD}=33.77 \pm 40.2 \mathrm{~s}$ ) and natural nests (mean $\pm \mathrm{SD}=27.8 \pm 16.1 \mathrm{~s}, \quad U=355.5, \quad P=0.678$ ). The rate of tail fanning was faster in the artificial (mean $\pm \mathrm{SD}=1.62 \pm 0.25 \mathrm{~s}$ per tail movement) than

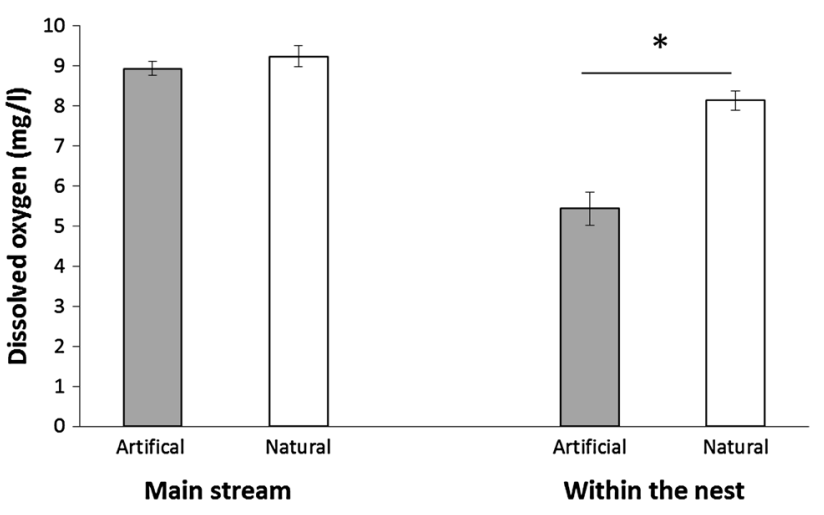

Fig. 2 Comparisons of dissolved oxygen levels between Ichikawa (artificial nest site) and Hino (natural nest site) River. *Statistically significant difference $(\alpha=0.05)$

natural nest (mean $\pm \mathrm{SD}=1.91 \pm 0.25 \mathrm{~s}$ per tail movement, $U=529.0, P=0.023$ ).

Dissolved oxygen

There was no significant difference in DO level in the stream center between the artificial (Ichikawa River) and natural nests (Hino River, $t=-0.952, d f=4, P=0.394$; Fig. 2). In contrast, the DO level within the artificial nest was significantly lower than that in the natural nest $(t=-$ 5.644, $d f=4, P=0.005)$. 


\section{Discussion}

The present study provides the first quantitative documentation of post-breeding behaviors displayed by male salamanders under natural conditions, which most likely increase the survivorship of the offspring (i.e., parental care; Trivers 1972). Among the observed behaviors, tail fanning, agitating and egg eating are possible paternal care behaviors. Although there was a trend of the natural-nest den-master displaying more rocking behavior, the difference was not statistically significant. Moreover, rocking behavior is probably not part of parental investment because this behavior was also observed in individuals without eggs, and has often been observed prior to molting (Okada and Fukuda, personal observation). Thus, we focus our further discussion on tail fanning, agitating and egg eating.

Tail fanning had been briefly described from the captive population of A. japonicus at Asa Zoological Park (Suzuki 1981, 1984). Our findings confirm that tail fanning is not unique to the captive individuals but also performed by den-masters under natural conditions. Paternal care is common among fish, and fanning (the fish uses not only its tail but also other fins) is one such behavior (Gross and Sargent 1985). For example, parental males of three-spined sticklebacks (Gasterosteus aculeatus; Reebs et al. 1984), and common gobies (Pomatoschistus microps; Jones and Reynolds 1999) increase fanning efforts for their eggs as DO levels decrease in order to replace deoxygenated water with more oxygenated water. This is because low DO levels result in unsuccessful development and hatching of the embryos (Hale et al. 2003). While increasing the survivorship of the young, weight loss of the parental males suggests that fanning is costly, especially in low oxygen environments (Jones and Reynolds 1999). In captive breeding of A. japonicus, it has been found that maintaining high DO levels is critical for successful hatching (Kobara 1985). Therefore, tail fanning by den-masters of $A$. japonicus likely serves as an important paternal care behavior that maintains dissolved oxygen level across eggs within nests and thus increases the survival of the young.

In our study, the den-master in the artificial nest, where the DO level was significantly lower than in the natural nest, displayed tail fanning for a greater percentage of time (on average $41 \%$ in the artificial vs. $1.6 \%$ in the natural nest). In contrast, there were no significant differences in the other possible parental care behaviors, namely agitating and egg eating between the two nests. In addition to the greater proportion of tail fanning effort, the artificial-nest den-master also fanned its tail faster than the natural-nest den-master. As in the above fish examples, our results suggest that parental male A. japonicus may alter fanning efforts depending on ambient DO levels and invest more under lower DO conditions. However, our sample size did not allow us to preclude the possibility that the individual difference, rather than the DO level difference, caused the difference in the time spent on, and the rate of, tail fanning.

There have been two brief reports of agitating the eggs with head and body from the captive population at the Asa Zoological Park (Suzuki 1981, 1984). Kuwabara and Nakagoshi (2009) also provided a very brief description of agitating behavior while recording the mating behaviors of A. japonicus in an artificial nest in nature. To improve hatching success of its eggs in captivity, Suzuki (1981, 1984) mimicked the agitating behavior by stirring the eggs a few times every or every other day, which resulted in the marked improvement of their hatching rate. Given that such a low frequency of agitation led to increased hatching success in captivity, this behavior likely functions differently from tail fanning which provides oxygenated water. Because of the relatively long embryonic period of A. japonicus (1-3 months; Tago 1927; Nussbaum 1987; Kuwabara et al. 2005), agitating eggs may be important in preventing yolk adhesions and developmental anomalies, as suggested in maternal care of plethodontid salamanders in which females also attend and agitate their eggs (Nussbaum 1985). It is important to note that our results revealed that agitating behavior was displayed much more frequently than the necessary frequency to ensure healthy embryo development in captivity (Suzuki 1981, 1984); both den-masters agitated the eggs every day on average $17 \%$ of the total recorded time in the natural and $26 \%$ in the artificial nest. Based on our observations of agitating behavior, we hypothesize that another function of agitation by a den-master is to guard against small insect predators and to monitor the overall health of his eggs.

Parental males of many fish species eat their own eggs while guarding them, known as filial cannibalism (Rohwer 1978). This behavior has evolved presumably because it allows a parental male to maximize life-time reproductive success by sacrificing a portion of the present brood for the future reproductive efforts through the acquisition of energy from the consumed eggs. Egg eating by the denmasters observed in our study appears to be different from such filial cannibalism. While den-masters may gain some energy via egg eating, their consumption of their own eggs noticeably targeted whiter eggs that were likely to be unfertilized, dead, or infected with water mold. In contrast, we observed that $A$. japonicus indiscriminatingly feed on eggs of unrelated individuals (Supplementary information, S4). We do not know how den-masters recognize such unhealthy eggs. Because of the typically very dark interiors of their nests, den-masters likely use chemical cues to identify dead eggs or those infected with water mold while agitating them. 
Aquatic eggs of various amphibian species suffer considerable mortality because of infection by water molds of Saprolegniaceae (Blaustein et al. 1994; Gomez-Mestre et al. 2006). In fact, water mold infection is a serious problem in rearing the eggs of $A$. japonicus in captivity (Suzuki 1984). Some pond-breeding amphibians without parental care, such as spotted salamander (Ambystoma maculatum) and wood frog (Lithobates sylvaticus), defend their eggs from water mold by wrapping the eggs with a jelly layer or accelerating timing of hatching (GomezMestre et al. 2006). In Cryptobranchid salamanders, which have long embryonic periods, removal of eggs that are already infected or will be infected with water mold likely increases the overall survivorship of the clutch and thus the fitness of the parental male. We term this selective consumption of their own eggs "hygienic filial cannibalism", and hypothesize that this behavior is adaptive because it prevents water mold infection from spreading to the healthy embryos.

A similar adaptive mechanism to hygienic filial cannibalism was tested in the sand goby (Pomatoschistus minutus) system. Klug et al. (2006) found that simulated partial-clutch cannibalism increased survivorship of the remaining sand goby eggs, presumably because of densitydependent egg survival. Furthermore, a mathematical model suggests that the evolution of filial cannibalism can be facilitated by selective consumption of lower-quality eggs (Klug and Bonsall 2007). These studies underpin selective forces for the evolution of hygienic filial cannibalism in A. japonicus and possibly other aquatic species whose eggs suffer water mold infection.

It is important to note that the inferences drawn from our results are limited by the small sample size (one natural and one artificial nest den-master). One of the challenges of observing parental care behaviors of Cryptobranchid salamanders is to find their natural nesting sites. These are well hidden by stream bank structures and vegetation. Even when nesting sites are located, it is rare to find nests whose structures are suitable for recording (i.e., a large enough entrance and a straight connection to the den). In contrast, it is easy to locate and record den-masters in artificial nests. However, artificial nests are not readily used by den-masters. There are three artificial nests in our research site, but only one, which we studied, has recently been used by a den-master. The artificial nest we examined has not been used since our study was carried out in 2011. These difficulties explain our small sample size and also the lack of empirical studies of parental care behaviors of Cryptobranchid salamanders under natural conditions.

Given their similar breeding habits, tail fanning, agitating and hygienic filial cannibalism are likely shared by the other members of Cryptobranchidae, Cryptobranchus alleganiensis and A. davidianus. In these species, males provide parental care, whereas maternal care is the norm in the vast majority of the salamander species with parental care (Nussbaum 1985). This rarity of paternal care among salamanders is best explained by the association hypothesis, which predicts that the sex with closer association with embryos provides parental care (Williams 1975; Gross and Shine 1981). All salamander species, except those in three families, Cryptobranchidae, Hynobidae and Sirenidae, fertilize internally via spermatophores (Reinhard et al. 2013), in which females develop a closer association with the embryos and thus are the care providers when parental care exists. In Cryptobranchidae, fertilization occurs externally, and males defend courtship grounds (i.e., nests) in order to sequentially mate with multiple females, as the females leave the nests after depositing the eggs (Nussbaum 1985; Kawamichi and Ueda 1998). In such a system, males provide parental care through the establishment of a closer association with the embryos, although paternal care in this case may have evolved secondarily to mating ground defense.

Nussbaum (1985) emphasizes the importance of parental care among salamander species that oviposit in streams. Because of the paucity of zooplankton in stream habitats, larvae of stream salamanders mainly feed on small insects. This feeding habit requires larger cranial and thus larger body size of larvae, which likely led to the evolution of larger eggs and longer embryonic periods in stream salamanders (Nussbaum 1985). In addition to the relatively long embryonic period, newly hatched larvae of A. japonicus do not forage for the first 2-3 months post-hatching (Kobara 1985). Although there are no data available on the feeding ecology of larval A. japonicus in natural habitats, this long embryonic and larval period without foraging might have evolved because their larvae need to undergo an ontogenetic shift and become large enough to start feeding on stream insects. Thus, tail fanning, agitating, and hygienic filial cannibalism are likely to be crucial in improving the survivorship of the eggs and possibly larvae during this long initial developmental period. Future studies should examine the extent of paternal care that denmasters exhibit for developing larvae until the larvae begin foraging and dispersing in the following spring (Kobara 1985).

Acknowledgments We thank Hiroko Yamasaki for the dissolved oxygen measurements, Etsuko Yuki for her assistance in videotaping the natural nest den-master, and Takeyoshi Tochimoto for his assistance in videotaping the artificial nest den-master. Yuki Taguchi kindly provided us with requested literature. We also thank Atsushi Koike for his mentorship and Toshifumi Wada, Rebecca Hale, and two anonymous reviewers for their valuable comments on the earlier draft. We are grateful to the Tottori and Hyogo Prefectural Boards of Education for the research permits. This research was in part funded by the grant for the Tottori University Research Project for Rural Sustainability. 


\section{References}

Andersson M (1994) Sexual selection. Princeton University Press, Princeton

Blaustein AR, Grant Hokit D, O'Hara RK, Holt RA (1994) Pathogenic fungus contributes to amphibian losses in the pacific northwest. Biol Conserv 67:251-254

Clutton-Brock TH (1991) The evolution of parental care. Princeton University Press, Princeton

Crump ML (1996) Parental Care among the Amphibia. in: Jay SR, and TS Charles (eds) Adv Study Behav. Academic, San Diego, pp 109-144

Dawkins R, Carlisle TR (1976) Parental investment, mate desertion and a fallacy. Nature 262:131-133

Duellman WE, Trueb L (1986) Biology of amphibians. Johns Hopkins University Press, Baltimore

Gomez-Mestre I, Touchon JC, Warkentin KM (2006) Amphibian embryo and parental defenses and a larval predator reduce egg mortality from water mold. Ecology 87:2570-2581

Gross MR, Sargent RC (1985) The evolution of male and female parental care in fishes. Am Zool 25:807-822

Gross MR, Shine R (1981) Parental care and mode of fertilization in ectothermic vertebrates. Evolution 35:775-793

Hale RE, St. Mary CM, Lindstörm K (2003) Parental responses to changes in costs and benefits along an environmental gradient. Environ Biol Fishes 67:107-116

Jones JC, Reynolds JD (1999) Oxygen and the trade-off between egg ventilation and brood protection in the common goby. Behavior 136:819-832

Kawamichi T, Ueda H (1998) Spawning at nests of extra-large males in the giant salamander Andrias japonicus. J Herpetol 32:133-136

Klug H, Bonsall MB (2007) When to care for, abandon, or eat your offspring: the evolution of parental care and filial cannibalism. Am Nat 170:886-901

Klug H, Lindström K, Mary CMS (2006) Parents benefit from eating offspring: density-dependent egg survivorship compensates for filial cannibalism. Evolution 60:2087-2095

Kobara J (1985) The giant salamander. Doubutsusha, Tokyo (in Japanese)

Kuwabara K, Nakagoshi N (2009) Analysis on reproductive behavior of Japanese giant salamander, Andrias japonicus —observations on the breeding behavior and notes on the video imagery. Nat Hist Nishi-Chugoku Mt 14:11-50 (in Japanese with English abstract)
Kuwabara K, Ashikaga K, Minamigata N, Nakanishi M, Shimada H, Kamata H, Fukumoto Y (2005) The breeding ecology and conservation of the Japanese giant salamander, Andrias japonicus, at Shijihara and Kamiishi in Tokyohira-cho, Hiroshima Prefecture. Nat Hist Nishi-Chugoku Mt 10:101-133 (in Japanese with English abstract)

McDonald JH (2009) Handbook of biological statistics. Sparky House, Baltimore

Nussbaum RA (1985) The evolution of parental care in salamanders. Museum of Zoology, University of Michigan, Ann Arbor

Nussbaum RA (1987) Parental care and EGG size in salamanders: an examination of the safe harbor hypothesis. Res Popul Ecol 29:27-44

Reebs SG, Whoriskey FG Jr, FitzGerald GJ (1984) Diel patterns of fanning activity, egg respiration, and the nocturnal behavior of male three-spined sticklebacks, Gasterosteus aculeatus L. (f. trachurus). Can J Zool 62:329-334

Reinhard S, Voitel S, Kupfer A (2013) External fertilisation and paternal care in the paedomorphic salamander Siren intermedia Barnes, 1826 (Urodela: Sirenidae). Zool Anz 253:1-5

Rohwer S (1978) Parent cannibalism of offspring and egg raiding as a courtship strategy. Am Nat 112:429-440

Salthe SN, Mecham JS (1974) Reproductive and courtship patterns. In: Lofts B (ed) Physiology of the amphibia. Academic, New York, pp 310-473

Smith BG (1907) The life history and habits of Cryptobranchus allegheniensis. Biol Bull 13:5-39

Suzuki N (1981) Oviposition and hatching of giant salamander in captivity. Bull Hiroshima City Asa Zoo 10:8-18 (in Japanese)

Suzuki N (1984) Review of the five consecutive year captive breeding of giant salamanders. Bull Hiroshima City Asa Zoo 13:7-13 (in Japanese)

Tago K (1927) Notes on the habits and life history of Megalobatrachus japonicus. Pp. 828-838. Xth Congrès International de Zoologie, enu à Budapest 1927, Budapest, Hungary

Tochimoto $T$ (1995) Ecological studies on the Japanese giant salamander, Andrias japonicus in the Ichi River in Hyogo Prefecture $X$ : an attempt to rebuild spawning places along the river. J Jpn Assoc Zool Gard Aquar 37:13-17 (in Japanese with English abstract)

Trivers RL (1972) Parental investment and sexual selection. In: Campbell B (ed) Sexual selection and the descent of man 1871-1971. Aldine, Chicago, pp 136-179

Williams GC (1975) Sex and evolution. Princeton University Press, Princeton 